\title{
Determining the Impact of Supervisory Support on Employee Engagement in the Telecommunication Sector of Ghana: The Role of Supportive Organizational Culture
}

\author{
Leslie Afotey Odai $\left(\mathbb{D} \otimes^{1}{ }^{1}\right.$, Jingzhao Yang ${ }^{2}$, Isaac Ahakwa ${ }^{(D)}{ }^{3}$, Mohammed Shaibu Ismaila ${ }^{4}$, \\ Samuel Dartey ${ }^{5}$ \\ School of Management, Jiangsu University, Zhenjiang, China ${ }^{1,2,3,4,5}$
}

\begin{abstract}
Purpose- Organizations that enforce effective supervisory support through their cultural traits see their employees reciprocating through positive outcomes. The study explored the impact of supervisory support on employee engagement in Ghana's telecommunications sector and the moderating effect of supportive organizational culture on the relationship.

Design/Methodology- A correlational descriptive research design was adopted. A sample of three hundred and fifty-three (353) employees was drawn randomly from a top selected telecommunication company in the Accra Metropolis of Ghana. Information collated were analyzed using Statistical Package for Social Sciences (SPSS version 26) and partial least square based on Structural Equation Modeling (SEM)

Findings- The findings indicate that supervisory support significantly influences employee engagement. Again it was revealed that supportive organizational culture influences employee engagement and substantially moderates the relationship between supervisory support and employee engagement.

Practical Implications- The findings provide valuable suggestions for organizations, managers, and supervisors to emphasize on measures such as a robust feedback system, training of supervisors, and enhancing employees' freedom to operate within the organization, which increases employee engagement and optimizing the organization's competitive advantage.
\end{abstract}

\section{ARTICLE INFO}

Received: February 20, 2021

Revised: February 28 \& Mar 23, 2021

Accepted: March 23, 2021

Published: April 1, 2021

\section{Keywords:}

Supervisory support

Employee engagement

Supportive organizational culture

(cc) BY (C) 2021 The Author(s)

$\bowtie$ Corresponding author: leslieodai3@gmail.com 


\section{Introduction}

Employee engagement continues to be a significant area of interest among researchers and organizations as engaged employees are highly involved, emotionally devoted, and exceedingly enthused about going beyond the call of duty whiles executing their tasks with excellence (Anitha, 2014). In situations whereby employees are intensely engaged in an organization, a highly positive and passionate feeling is stirred up to strive harder for the organization's success (Othman et al., 2017). Previous research has revealed that highly engaged employees are regarded as assets to the organization and serve as a reference point for retaining a talented and experienced workforce. In contrast, disengaged employees are considered ones who burden the organization, bringing about training costs, lower profitability, and absenteeism (Al Shehri et al., 2017). An engaged employee is considered emotionally attached to the organization, passionate about their work, and prioritizes the organization's success (Seijts \& Crim, 2006). Research on employee engagement has identified numerous predictors, work or personal-related factors, to induce changes in employee behaviors by increasing engagement (Bakker, 2011). Availability and productive use of a type of work-related factor such as supervisory support have been proven to be a significant determinant in improving employee engagement (Hallberg et al., 2007). According to Masterson et al. (2000), an employee comes across two essential social exchange relationships in their workplace; one is the relationship with their direct supervisor. The other is the relationship with the organization. In an operational environment, supervisory support is considered to be a critical job-related resource because it contributes to the achievement of employee goals while reducing stress and workload, which, in turn, translates into better-engaged employees (Bakker et al., 2004). Supervisory support can be expressed as the rate at which supervisors provide help and support to employees in all aspects of business within the working environment through continuous interaction between the supervisor and employees (Aksoy \& Yalçınsoy, 2017).

One of the largest and most efficient sectors in Ghana is undoubtedly the telecommunication sector. This highly competitive sector is experiencing tremendous rapid development with an enormous contribution to the Ghanaian economy's growth (Kumi et al., 2020). Employees' high involvement in their work roles in this industry will see it as a tremendous force to reckon with. Several researchers have asserted that engaged employees enable an organization to harness opportunities, aiming to intensify its competitive advantage, which translates into an improvement in organizational performance by retaining their talents (Rabiul \& Rubel, 2013). It is argued by Rabiul and Rubel (2013) that supervisor's role acts as a contributing factor in affecting employee's attitudes and behavior toward the organization, which may constitute a turnaround in the employee's performance within the organization.

Numerous studies on supervisory support and employee engagement have been conducted all over the world. Examples of such studies include supervisory support as a determinant of employee engagement in Information Technology and enabled service sector of India (Dapke \& Patole, 2014). Results revealed supervisory support as a factor that impacts employee engagement positively. Vera et al. (2016) examined the influence of supervisory support on employee engagement of nurses in Portugal. Results reported indicated effective support from supervisors as a promoter of engagement in employees. Holland et al. (2017) investigated the association between supervisory support and employee engagement of Australian nurses where supervisory support was positively associated with employee engagement. Likewise, another study explored the effect of supervisory support on employee engagement among business process outsourcing employees in Metro Manila, Philippines (Ocampo et al., 2018). The findings revealed a significant effect of supervisory support on employee engagement. Sawasdee et al. (2020) also determined supervisory support and its role on employee engagement among employees of pharmaceutical companies of Thailand. Employee engagement was influenced by effective supervisory support, causing employees to reciprocate through job performance. In the Ghanaian context, Ashley (2018) investigated the association between employee engagement and organizational commitment within the banking sector. Ohemeng et al. (2020) also investigated employee engagement and its association with task performance. However, studies about employee engagement and supervisory support are lacking in 
the Ghanaian context. Few studies conducted are mainly focused on sectors such as the banking, hospitals and education to the detriment of the telecommunication sector in Ghana. This research aims to fill a gap in studies within the telecommunications industry in Ghana, as well as add to the existing literature.

Even though most studies have looked at the relationship between supervisory support and employee engagement, none have incorporated supportive organizational culture as a moderating factor in the relationship between supervisory support and employee engagement. Therefore, this study fills the gap by introducing supportive organizational culture as a moderating variable amid the two variables in the Ghanaian Context. The study used more modern techniques in the analytical process through partial least squares (PLS) based on structural equation modeling (SEM). The study employed the new techniques of assessing the predictive relevance of the model "PLS predict," as proposed by (Shmueli et al., 2019)

The study outcome would help organizations to be well placed in creating a solid and appealing brand image. Again, the study's findings will inform the decision of policymakers within organizations to come out with effective strategies aimed at strengthening the existing and development of new support policies within the organization. Moreover, the results will help service providers conform to the National Communication Authority (NCA). Finally, more modernized scientific data regarding the study constructs are provided by the research to current human resource management literature in Ghana. This contributes significantly to the body of knowledge and will serve as an essential reference material for academicians interested in diving deeper into the study area.

\section{Literature Review}

\section{Supervisory Support}

The relationship between supervisors and subordinates is referred to as supervisory support, where subordinates view such relationship as being a significant contributing factor to their career development (Sattavorn, 2018). Provision of help in that manner is essential for inspiring, retaining, and developing workers with skills and knowledge (Barbara et al., 2005). According to Powell (2011), Supervisory support means that managers observe employee's contributions and care about their well-being. It is the perception of employees that organizational managers empathize with them, support and inspire them (Burke et al., 1992). A piece of helpful information in the form of performance feedback provided by supervisors to their subordinates contributes heavily to the organization's career advancement opportunities. If employees receive adequate support from their managers, such employees will show positive behavior towards their organization (Ahmad et al., 2016).

Research has indicated that when employees perceive an environment that is reassuring in every fold from their supervisors, the possibility of lending a supporting hand to their supervisors and contributing to the realization of organizational goals is inevitable (Eisenberger et al., 2002). As Jernigan \& Beggs (2005) stated, a supervisor's behaviors and actions strengthen a subordinate's positive attitudes and spirit, which should summon a sense of ethical commitment in subordinates. They further asserted that employee satisfaction with their supervisors could be an essential facet of a personal commitment to the organization. Employees highly value supervisory support with a strong desire to be respected, loved by their executives, and cherished for their contributions. People's behavior becomes magnified following their environs and the people they interact with (Aksoy \& Yalçınsoy, 2017).

\section{Employee Engagement}

Employee engagement is still a vital issue for organizations, with leaders facing the urgency of seeing to it that engagement of their staff is maintained (Kapoor \& Meachem, 2012). The definition of employee engagement continues to evolve, having received significant attention in academic research (Macey \& Schneider, 
2008). The concept was first postulated by Kahn (1990), defining employee engagement as "organizational members utilization of themselves to assigned duties." The researcher further emphasized that engagement can be characterized as being expressed emotionally, physically, and cognitively during the execution of an assigned task. Schaufeli \& Bakker (2004) described employee engagement as a progressive and self-fulfilling work-related facet, denoted by dedication, vigor, and absorption. Dedication is defined as the traits of enthusiasm, pride and inspiration demonstrated whiles working; Vigor showcases the extra push and resilience to withstand hindrances in the face of work and absorption is characterized by strong attachments with ones work in a manner where time flies swiftly and one has troubles parting away from work.

According to Gallup (2002), employees can be described in three facets: non-engaged employees, engaged employees and actively disengaged employees. Non-engaged employees place emphasis only on designated duties rather than organizational goals. Engaged employees are dedicated builders who pursue excellence in their positions. Actively disengaged employees are treacherous individuals who struggle to perform well and discourage the performer in the organization. An engaged employee is very instrumental in achieving essential business performance outcomes as considerable evidence proves that engaged employees showcase a high degree of customer satisfaction and loyalty to the organization, highly productive and more profitable compared to less involved employees (Chalofsky, 2010; Saks, 2006; Shuck \& Reio, 2014).

\section{Supportive Organizational Culture}

The idea of organizational culture has been acknowledged as an essential component of organizational behavior and a valuable concept to explain better how organizations work (Kristof, 1996). Organizational culture is referred to as the collection of beliefs, norms, values, and the identification of organizational members with core claims, which includes the organization's goals, missions, practices, and policies (Hofstede et al., 1990; Khazanchi et al., 2007). It was defined by (Schein 1996) "as basic assumptions conceived, created or unearthed by a specific group as it looks out to manage its internal integration and external adaptation issues.”

Supportive organizational cultures support open relationships among employees, acting as a contributing factor to a friendly working environment and employees that stay on the lookout for themselves (O'Reilly et al., 1991). According to Wallach (1983), supportive culture is reflected when employees work with the team, and they trust and encourage each other. He further postulates that supportive organizational culture is characterized by an environment that is safe, equitable, friendly, encouraging, trusting, relationship-oriented, and collaborative. Berson et al. (2008) assert that a supportive culture fosters a collaborative, accommodating, and welcoming environment in general.

\section{Supervisory Support and Employee Engagement}

Employee's perceptions constitute one of the essential factors that contribute to behavior and attitudes and, therefore, engagement (Shusha, 2013). Supervisors within an organization play a crucial role in ensuring that employee's perceptions about the organization are developed due to employees perceiving their supervisors as representatives (Deconinck \& Johnson, 2009). Theoretically, the relationship between supervisory support and employee engagement is explained by the social exchange theory. The social exchange theory postulates that when a consistently indulged employee by a key actor in the place of work assesses the relationship as one that is unbiased and satisfactory, that employee is likely to reciprocate through a better performance on the job and voluntary positive work demeanors and behaviors (Ladebo, 2008). According to Blau (1964), the foundation of a social exchange relationship stems from a circumstance whereby one party contributes to the other party.

Investigations undertaken by Otken and Erben (2010) revealed that employees in an organization who are constantly receiving positive feedback from their supervisors become more engaged as such interactions bring about employee behavior changes. It was further shown that in situations where employees are valued 
and cared for by their supervisors, it strengthens their sense of oneness with the firm, which influences employee dedication, energy levels, and sense of joy at work, creating an ambiance where detachment from work becomes challenging.

Swanberg et al. (2011) examined the mediating role of supervisory support and schedule satisfaction on schedule control and employee engagement. The study outcome revealed that supervisory support is significantly related to employee engagement as it was found to be an essential element in the engagement process. The authors further suggested that firms concerned with improving engagement in their employees will need to introduce successful techniques to train supervisors on ensuring adequate-time limit management for front-line workers.

A similar study conducted by Rabiul and Rubel (2013) revealed that supervisory support significantly influences employee engagement as support from both the supervisors and the organization in addressing employee needs was instrumental in affecting employee engagement. These discoveries are backed by past studies (Holland et al., 2017; Mohamed \& Ali, 2016). From the above literature, this study, therefore, proposes that;

H1: Supervisory support positively influences employee engagement.

\section{Supportive Organizational Culture, Supervisory Support, and Employee Engagement}

Numerous world-renowned researchers agree that the connection between employees and the prevailing culture within an organization is crucial to the organization's success (Cameron \& Quinn, 2011). Between and within organizations exist different cultures, where such cultures may bring forth good or despicable behaviors of employees (Warrick et al., 2016). A study conducted by Asiedu (2015) in connection to how supportive organizational culture affects job satisfaction within the Oxford banking company revealed that the employees of the organization were not inspired enough to put in their best efforts due to the non-existence of a rewarding culture, communication culture, developmental opportunities culture, and culture of supervisory support. Findings further revealed that the non-existence of supportive organizational culture brought about less committed and less engaged employees. Most of them switched to other companies where conditions were perceived to be conducive.

According to Brenyah \& Darko (2017), supportive organizational culture involves relationships described by trust and mutuality. They further asserted that organizations with supportive cultures exist primarily to attend to the needs of their members. As such, individuals within the organization are expected to influence one another through examples and assistance. Study outcome of the researcher's connection to the influence of organizational culture on employee engagement revealed that a supportive culture has a positive and substantial impact on employee engagement. The findings implied that an organization with supportive culture indicates mutual trust among individuals and organization leaders, which causes employees to be engaged. This is consistent with previous research results (Macey \& Schneider, 2008; Njuguna, 2016). On the back of the above evidence, the study suggests that;

H2: Supportive organizational culture positively affects employee engagement.

H3: Supportive organizational culture moderates the relationship between supervisory support and employee engagement. 


\section{The Conceptual Framework}

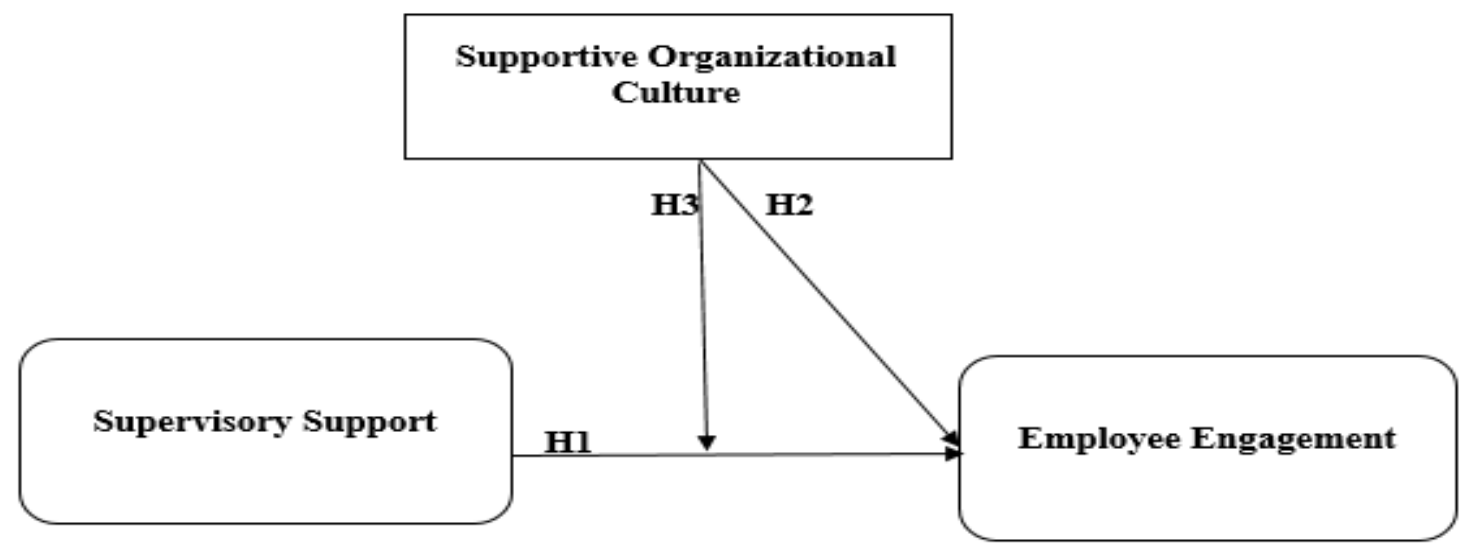

Figure: 1 Conceptual framework

\section{Methodology}

\section{Research Design}

A research design is a structured approach harnessed by a researcher to carry out a study. The study adopted a survey-based research design where a correlational descriptive research design was adopted to examine the association among the study constructs.

\section{Research Population}

The population of research refers to the whole group of objects or individuals essential to the research project. The population considered by the study were employees from top established telecommunications companies in the Accra metropolis of Ghana (MTN, AirtelTigo, and Vodafone).

\section{Research Sampling and Sample Size}

The study capitalized on the usage of both probability and non-probability sampling techniques. A judgmental sampling technique was used to select branches of each established top telecommunications company within the Accra metropolis of Ghana from which the employees were selected. Judgmental sampling enables researchers to select units to be sampled according to their existing knowledge or professional judgment. To ensure that employees have a fair chance of being chosen from the target population, the study adopted a simple random sampling technique to choose the needed number of employees from the branches of each established top telecommunications company (MTN, AirtelTigo, and Vodafone). Simple random sampling is reported to be a method that showcases a larger population's precise representation and is characterized by a less tedious technique. The study's sample size was three hundred and fifty-three (353) respondents, representing employees from the telecommunications company's selected branches. A hundred and fifty (150) employees were selected from branches of MTN, followed by one hundred and three (103) from branches of Vodafone and one hundred (100) from branches of AirtelTigo within the Accra Metropolis of Ghana.

\section{Research Instrument, Data collection, and Measurement Variables}

The study adopted a primary data source, enabling researchers to gather immediate information concerning specific issues regarding the study scope. A questionnaire was the research tool adopted by the 
study. A close-ended online questionnaire survey tool was created and distributed through various online platforms to the target respondents (employees from branches of the top established telecommunications company). A total of three hundred and seventy (370) questionnaires were sent through online applications to the selected target respondents. Out of the total, three hundred and fifty-three (353), representing a response rate of $94 \%$, were retrieved and subsequently used for the analysis. The remaining seventeen (17) were rejected due to missing values found in the responses.

For the variables presented in the study's conceptual framework to be operationalized, 16 items drawn and modified from previous research were subsequently used to measure the study constructs. Employee engagement was measured using six (6) items by (Schaufeli \& Bakker, 2003). The study also measured supervisory support using four (4) items from (London 1993) and six (6) items from Wallach (1983) that were used to measure supportive organizational culture. A 5-points Likert scale was used to measure all items, with 1 indicating strongly disagree and 5 indicating strongly agree.

\section{Data Analysis}

Data retrieved from the online survey questionnaire portal were exported into Microsoft Excel for ease of transferability and accessibility to various analysis tools. SPSS version 26.0 and smart PLS 3.0 were utilized to analyze the data where the study's demographic features were generated and the study model analyzed. Measurement models for the reliability and validity of measures were checked to ensure the adequate fit of data for the structural model. Loadings and significance of the path coefficients were analyzed and tested using the bootstrapping method (5000 resamples). The hypothesis formulated in the study were tested by assessing the structural model.

\section{Results and Discussions}

\section{Demographic Features of Respondents}

Presented below are the gender, age, educational level, and work experience of respondents.

Table 1: Demographic distribution of respondents.

\section{Demographic characteristics}

Gender

Age

Educational level

Work Experience

\section{Male}

Female

18-25 years

26-39 years

40 years and above

Diploma

HND

Bachelor degree

Post-graduate degree

Below 1 year

1-5 years

6-10 years

\section{Percentage (\%)}

\section{6}

45.4

34.7

54.1

11.2

20.6

26.2

44.8

8.4

7.1

32.2

60.7

Out of three hundred and fifty-three (353) participants, 54.6\% were males, whiles $45.4 \%$ represented females. It was ascertained that $34.7 \%$ fell within the age range of $18-25$ years, followed by a majority of $54.1 \%$ representing those within the age category of 26-39 years and $11.2 \%$ making up those of age 40 years and above. Again, $20.6 \%, 26.2 \%, 44.8 \%$, and $8.4 \%$ constituted the level of education attained by respondents being Diploma, HND, Bachelor degree, and Post-graduate degree. Finally, it was discovered that $7.1 \%$ of respondents 
have worked with their respective companies for a duration of half a year, 1-5 years, and the majority representing 6-10 years.

\section{Evaluation of the Measurement Model}

The relationship between the study constructs was established using Smart Pls Algorithm, bootstrapping, and blindfolding technique. Data retrieved were analyzed for internal consistency reliability, convergent, and discriminant validity (refer to Table 2).

Table 2: Model reliability and validity

\begin{tabular}{|c|c|c|c|c|c|}
\hline Construct & Notations & Loadings & $\begin{array}{c}\text { Cronbach } \\
\text { Alpha } \alpha\end{array}$ & AVE & $\begin{array}{c}\text { Composite } \\
\text { reliability }\end{array}$ \\
\hline \multirow[t]{6}{*}{ Employee Engagement } & EE1 & 0.892 & 0.980 & 0.912 & 0.984 \\
\hline & EE2 & 0.988 & & & \\
\hline & EE3 & 0.987 & & & \\
\hline & EE4 & 0.980 & & & \\
\hline & EE5 & 0.980 & & & \\
\hline & EE6 & 0.900 & & & \\
\hline \multirow[t]{4}{*}{ Supervisory Support } & SP1 & 0.686 & 0.765 & 0.581 & 0.847 \\
\hline & SP2 & 0.783 & & & \\
\hline & SP3 & 0.754 & & & \\
\hline & SP4 & 0.821 & & & \\
\hline \multirow[t]{6}{*}{ Supportive organizational culture } & SOC1 & 0.975 & 0.981 & 0.912 & 0.984 \\
\hline & SOC2 & 0.974 & & & \\
\hline & SOC3 & 0.982 & & & \\
\hline & SOC4 & 0.954 & & & \\
\hline & SOC5 & 0.929 & & & \\
\hline & SOC6 & 0.914 & & & \\
\hline
\end{tabular}

Note: EE, (Employee Engagement); SP, (Supervisory Support); SOC, (Supportive Organizational Culture);

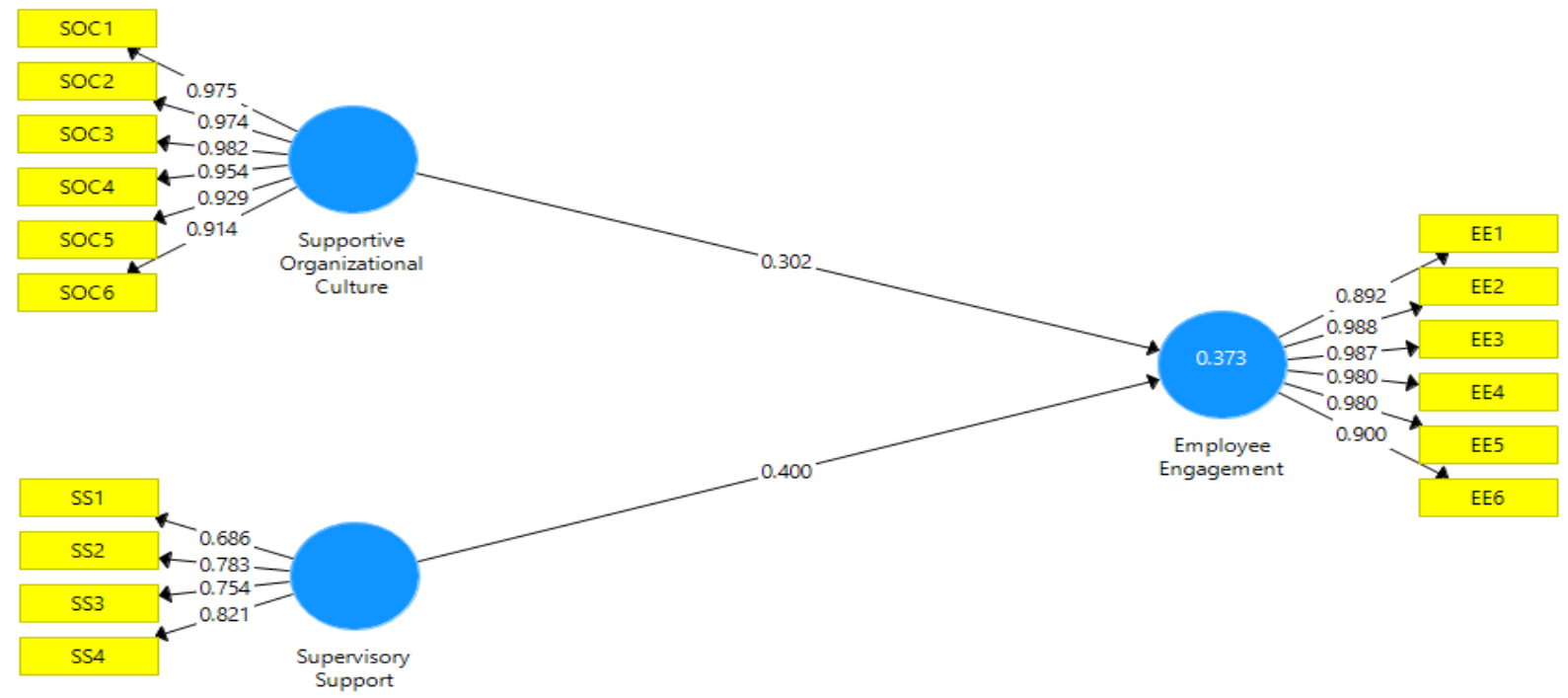

Figure 2: Structural model (direct relationship) 
Table 2 showcases the values of Factor loadings, Cronbach $\alpha$, average variance extracted (AVE), and composite reliability. Factor loadings of all the indicators were more significant than the threshold value of 0.6 as recommended by (Chin et al., 2008). The validity of the measurement model was established by both convergent validity and discriminant validity. Composite reliability (CR) and average variance extracted (AVE) recommended values were used in determining convergent validity. The convergent validity for the measurement model was found to be sufficient as all the constructs of the measurement model's value for Composite reliability (CR) and average variance extracted (AVE) exceeded the values of 0.70 and 0.50 , respectively, as suggested by (Hair jr et al., 2016). The measure of internal consistency of all item sets, determined by the Cronbach alpha, surpassed the suggested value of 0.70 (Hair jr et al., 2016) (refer to Table 2).

Table 3: Collinearity values evaluated by VIF

\begin{tabular}{cc}
\hline Construct's & VIF \\
\hline EE1 & 1.823 \\
EE2 & 1.879 \\
EE3 & 1.645 \\
EE4 & 1.957 \\
EE6 & 1.931 \\
SOC1 & 1.826 \\
SOC2 & 1.523 \\
SOC3 & 1.801 \\
SOC4 & 1.826 \\
SOC5 & 1.556 \\
SOC6 & 1.673 \\
SP1 & 1.612 \\
SP2 & 1.631 \\
SP3 & 1.499 \\
SP4 & 1.805 \\
\hline
\end{tabular}

Table 3 showcases the various constructs' collinearity values, evaluated by a variance inflation factor (VIF) to assess collinearity issues. Evaluations revealed no collinearity problems in the model (Ahakwa et al., 2021), as VIF values for all constructs were below the threshold of 5 (Kim, 2019).

Table 4: Fornell / Larcker's criterion for Discriminant V alidity

\begin{tabular}{llll}
\hline Constructs & EE & SP & SOC \\
\hline Employee Engagement & $\mathbf{0 . 9 5 5}$ & & \\
Supervisory Support & 0.552 & $\mathbf{0 . 7 6 2}$ & \\
Supportive Organizational Culture & 0.504 & 0.506 & $\mathbf{0 . 9 5 5}$ \\
\hline
\end{tabular}

The degree to which measures are not a duplication of other variables constitutes discriminant validity. It is accomplished by examining the low correlations between measures of interest and other latent construct measures. In accordance with the criterion of Fornell \& Larcker (1981), it is indicated that each construct's AVE square root (bolded diagonal values) is greater than its corresponding correlation coefficients, confirming a sufficient discriminant validity (refer to Table 4). 
Table 5: Heterotrait-Monotrait Ratio (HTMT) criterion for Discriminant Validity

\begin{tabular}{lcc}
\hline Constructs & $\mathbf{1}$ & $\mathbf{2}$ \\
\hline Employee Engagement & & \\
Supervisory Support & 0.611 & \\
Supportive Organizational Culture & 0.509 & 0.556 \\
\hline
\end{tabular}

Particular contemporary objection to the criteria of Fornell \& Larcker (1981) is of the view that the latter criteria do not identify the absence of discriminant validity in an effective manner (Henseler et al., 2015). Henseler et al. (2015) suggest another approach to measure the discriminant validity on the HTMT ratio criterion. The study used this approach to test for the model's discriminant validity, of which findings revealed values of HTMT ratio to be below 0.85 as suggested by (Kline 2011) (refer to Table 5). According to Kline (2011), values of the HTMT ratio more significant than the threshold of 0.85 indicate a problem of a model's discriminant validity.

\section{Hypothesis Testing and Structural Model Analysis}

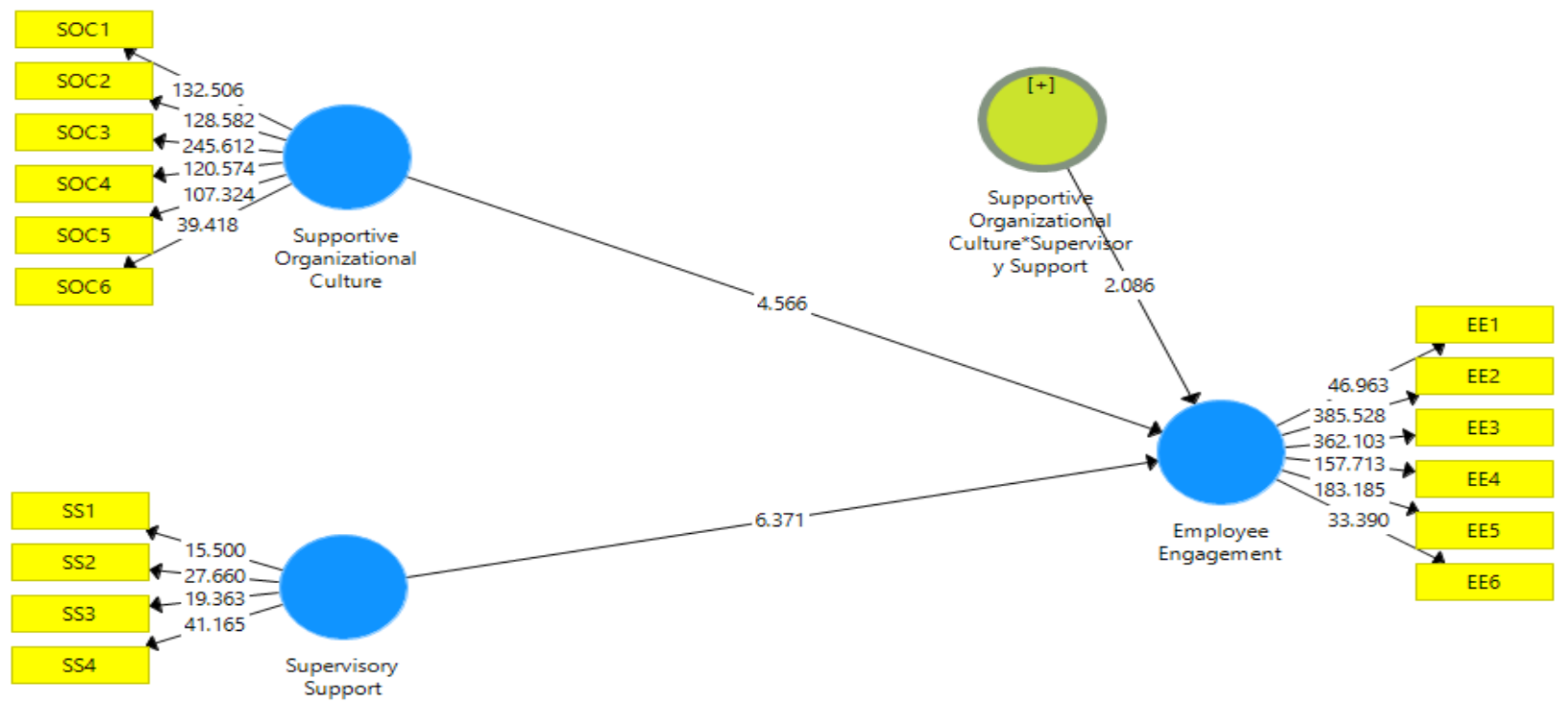

Figure 3: Structural model (Moderating effect)

Table 6: Hypotheses Testing.

\begin{tabular}{lcccc}
\hline Hypotheses & $\begin{array}{c}\text { Path } \\
\text { Coefficient }(\boldsymbol{\beta})\end{array}$ & $\begin{array}{c}\text { t-statistics } \\
\text { H1: SP -> EE }\end{array}$ & $\begin{array}{c}\text {-value } \\
(\mathbf{p})\end{array}$ & Decision \\
H2: SOC-> EE & 0.490 & 6.371 & 0.000 & Supported \\
H3: SOC*SS-> EE & 0.282 & 4.566 & 0.000 & Supported \\
\end{tabular}

The study used path coefficient, t-statistics, and the corresponding P-values to provide empirical support for the study construct's proposed hypothesis. In assessing the structural model, the relationships between the study constructs were examined using the bootstrapping technique. Findings revealed that 
supervisory support positively and significantly affected employee engagement $(\beta=0.490 ; \mathrm{t}$-value $=6.371 ; \mathrm{p}<$ 0.000). Findings again revealed that Supportive organizational culture positively and significantly affected employee engagement with a path coefficient of $(\beta=0.282$; $\mathrm{t}$-value $=4.566 ; \mathrm{p}<0.000)$.

Again, the study made use of a product indicator approach to assess the moderating effect of supportive organizational culture on the association between supervisory support and employee engagement. Findings revealed that Supportive organizational culture positively and significantly moderates the relationship between supervisory support and employee engagement $(\beta=0.147$; $\mathrm{t}$-value $=2.086 ; \mathrm{p}<0.037)$. All the hypotheses formulated in the study (H1, H2, H3) were thus supported (refer to Table 6).

Table 7: Effects Size

\begin{tabular}{lccc}
\hline Relationships & fsquare $\left(\boldsymbol{f}^{2}\right)$ & Effect size \\
\hline SS -> EE & 0.189 & Medium \\
SOC->EE & 0.108 & medium \\
Predictive Relevance & & Adjusted $\left(R^{2}\right)$ & $Q$ square $\left(Q^{2}\right)$ \\
Constructs & $R$ square $\left(R^{2}\right)$ & 0.369 & 0.313 \\
EE & 0.373 & & \\
\hline
\end{tabular}

Furthermore, to measure each construct's effect on another, the study used Cohen's (1988) guidelines, suggesting that values of $0.02,0.15$, and 0.35 represent small, medium, and large effects. Table 7 indicates that all effect size values $\left(f^{2}\right)$ of relationships on employee engagement had a significant positive medium effect. Moreover, supervisory support and supportive organizational culture explain $37.3 \%$ of the variance in employee engagement. The $R^{2}$ value of 0.373 is higher than the value of 0.26 that Cohen (1988) would showcase a substantial model.

Regarding the effect size of $\mathrm{f}^{2}$ and $\mathrm{R}^{2}$, the predictive sample reuse technique $\left(\mathrm{Q}^{2}\right)$ can also effectively illustrate predictive relevance (Chin et al., 2008). Based on the blindfolding procedure, $\mathrm{Q}^{2}$ shows how well data can be reconstructed empirically using the PLS parameters model. $\mathrm{Q}^{2}$ was obtained using crossvalidated redundancy procedures. A $\mathrm{Q}^{2}$ greater than 0 implies that the model has predictive relevance, whereas a $\mathrm{Q}^{2}$ less than 0 indicates that it lacks predictive relevance. $\mathrm{Q}^{2}$ for all endogenous variables demonstrate acceptable predictive relevance (refer to Table 7).

Table 8: Assessment of Manifest Variable

\begin{tabular}{cccccc}
\hline PLS & RMSE & Q $^{2}$ predict & LM & RMSE & $\begin{array}{c}\text { (PLS RMSE)-(LM } \\
\text { RMSE) }\end{array}$ \\
\hline EE1 & 0.420 & 0.407 & EE1 & 0.423 & -0.003 \\
EE2 & 0.459 & 0.319 & EE2 & 0.461 & -0.002 \\
EE3 & 0.445 & 0.322 & EE3 & 0.450 & -0.005 \\
EE4 & 0.445 & 0.334 & EE4 & 0.451 & -0.006 \\
EE5 & 0.478 & 0.306 & EE5 & 0.486 & -0.008 \\
EE6 & 0.536 & 0.259 & EE6 & 0.538 & -0.002 \\
\hline
\end{tabular}

*RMSE: Root Mean Squared Error; *LM: Linear Regression Model, EE, (Employee Engagement).

Evaluation of the PLS-SEM Q ${ }^{2}$ predicts values for all the indicators of the measurement model were conducted about the recommended guidelines of (Shmueli et al., 2019) in assessing the prediction error degree. Table 8 reveals that all the $\mathrm{Q}^{2}$ predict values are greater than zero $(0)$, demonstrating a highly symmetrical distribution of prediction errors. The naïve LM benchmark (refer to table 10) was compared with the PLSRMSE values, whereby the PLS-RMSE values produce a less forecast error for all indicators. The model estimation using PLS-RMSE values of EE1-EE2 are 0.420, 0.459, 0.445, 0.445, 0.478, and 0.536 respectively, whereas, in relation to these indicators, RMSE values produced by LM are $0.423,0.461,0.450,0.451,0.486$ and 
0.538. The model, therefore, has a high predictive power since negative figures, as presented in table 8 , indicate that all indicators of PLS-RMSE are less than the values of naïve LM-RMSE.

\section{Discussion}

The goal of the study was to look into the impact of supervisory support on employee engagement in Ghana's telecommunications sector and the role of supportive organizational culture as a moderator between the two. Results arrived at, disclosed that supervisory support had a significant and positive impact on employee engagement levels. This result backed past studies where supervisory support was proved to be a substantial determinant of employee engagement (Holland et al., 2017; Mohamed \& Ali, 2016; Swanberg et al., 2011). Otken and Erben (2010) postulate that a healthy relationship between supervisors and employees is essential for employees to attain higher performance levels and cultivate positive attitudes. Therefore, it is deserving of employees that supervisors will provide the needed support necessary to help employees execute their activities to make them more engaged and enhance their belongingness with the organization. (Rabiul \& Rubel, 2013). The constant effort of supervisors to indulge employees, such as asking how they can help employees with duties assigned them without assuming that they know it all and showing personal consideration, helps in shaping and enhancing employees involvement in their work roles which in the long run allows organizations to cut down cost and channel their energy into providing and ensuring high-quality service. A cost reduction will also result in fewer service charges, thus freeing customers from outrageous charges of network operators.

The study findings again revealed that supportive organizational culture significantly and positively influences employee engagement. This result falls in line with previous studies where supportive organizational culture greatly impacted employee engagement (Brenyah \& Darko, 2017; Njuguna, 2016). Moreover, the study findings revealed that supportive organizational culture positively moderates the relationship between supervisory support and employee engagement. Results further indicated that an organization with a cultural trait of trust encourages open relationships where employees can communicate freely with their co-workers and, most notably, their supervisors. Such genuine relationships are vital to empowering employees to offer more ideas and solutions, which helps an organization in its competitive advantage. Mutual trust between employees and individuals within an organization serves as a positive mind shifter of employees, which causes them to become attached to the organization and thus becoming engaged (Njuguna, 2016). An essential factor contributing to employee engagement stems from a trusting and supportive work environment (Macey \& Schneider, 2008). Organizations that create an ambiance where employees perceive themselves as significant contributors to the organizations' image and brand empower their workforce to always go above and beyond what is expected of them while performing their duties. Such behaviors make an organization and its human resource attractive to customers and potential candidates who wish for their services to be engaged by such firms.

\section{Conclusion}

Conclusively, because supervisors are considered as representatives of the organization, attitudes, and behaviors of employees can be influenced positively when employees perceive a high level of support from the supervisors, which in turn reflects organizational support. Again a supportive culture that encourages open relationships brings about a positive turnaround in employee's overall performance, which causes employees to become engaged, thus supporting the social exchange theory.

\section{Practical Implication}

The study findings supporting and adding up to previous studies assert that supervisory support has a significant influence on employee engagement with a supportive organizational culture, strengthening the association between the phenomenon under study. Given this, the findings suggest that management must 
make deliberate efforts to improve communication networks within the organization. With that being said, twoway communication that gives room to employees to make essential inputs and voice out an issue of concern freely without them being ignored or queried must be encouraged.

Again, since employees are usually in constant interaction with their supervisors, efforts must be put into conducting training programs to enhance their interpersonal skills. This will promote positive interaction between employees and supervisors, leading to changes in employee attitudes. Supervisors must also learn to give employees room for personal growth and development by allowing employees to use approaches as deemed fit to carry out activities as long as the desired result is being met. Different approaches to supervision must be adopted by supervisors when dealing with employees due to the differences in demographic characteristics of employees. Management must ensure that a robust feedback system is instilled among organizational members, whereby employees get equipped with the necessary information and support needed to undertake their task. Again, managers can consider the development of different support policies with the needs of employees in mind. Furthermore, a strong culture that promotes mutual respect among organizational members must be promoted as this catalyzes increasing employee engagement.

\section{Limitation and Future Direction}

Like any other research, the study has constraints of its own. The study focused only on three top established telecommunications companies within the Accra metropolis of Ghana. Again the study adopted only quantitative research method. Researchers recommend that further studies consider expanding the study scope to cover other regions and other telecommunication companies within the country to make the findings generalizable. Future studies can use a mixed method of research to gain new insights into the study's association. A similar analysis can be conducted using the same constructs in other sectors other than that of this study to arrive at different outcomes.

Funding: This research received no external funding.

Acknowledgments: We acknowledge there was no external funding support; all authors contributed accordingly in every part of the paper.

Conflicts of Interest: The authors declare no conflict of interest.

\section{References}

Ahakwa, I., Tackie, E. A., Odai, L. A., Dartey, S., \& Yang, J. (2021). The Effects of Job Autonomy, Organizational Learning, and Work Environment on Organizational Commitment of Public Sector Employees in the Ashanti Region of Ghana. Article in International Journal of Scientific Research and Management. https://doi.org/10.18535/ijsrm/v9i1.em02

Ahmad, A., Bibi, P., \& Majid, A. H. A. (2016). Co-worker support as moderator on the relationship between compensation and transactional leadership in organizational commitment. International Journal of Economic Perspectives, 10(4), 695-709.

Aksoy, C., \& Yalçınsoy, A. (2017). Investigation on the Relationship Between Job Satisfaction, Organizational Commitment, Organizational Justice and Supervisor Support: an Application in the Health Sector. Journal of Management Research, 10(1), 26. https://doi.org/10.5296/jmr.v10i1.12074

Al Shehri, M., McLaughlin, P., Al-Ashaab, A., \& Hamad, R. (2017). The Impact of Organizational Culture on Employee Engagement in Saudi Banks. Journal of Human Resources Management Research, 2017, 1-23. https://doi.org/10.5171/2017.761672

Ashley, N. (2018). ASSESSING THE RELATIONSHIP BETWEEN EMPLOYEE ENGAGEMENT AND ORGANIS ATIONAL COMMITMENT IN A BANKING ENVIRONMENT IN GHANA $A$ dissertation submitted in fulfilment of the requirements for the degree of Master of Commerce in Human Resource Management School of Management, IT and Governance College of Law and Management Studies. 
https://researchspace.ukzn.ac.za/handle/10413/18270

Asiedu, E. (2015). Supportive Organizational Culture and Employee Job Satisfaction: A Critical Source of Competitive Advantage. A Case Study in a Selected Banking Company in Oxford, a City in the United Kingdom. International Journal of Economics \& Management Sciences, 04(07). https:// doi.org/10.4172/21626359.1000272

Bakker, A. B. (2011). An Evidence-Based Model of Work Engagement. Current Directions in Psychological Science, 20(4), 265-269. https://doi.org/10.1177/0963721411414534

Bakker, A. B., Demerouti, E., \& Verbeke, W. (2004). Using the job demands-resources model to predict burnout and performance. Human Resource Management, 43(1), 83-104. https://doi.org/10.1002/hrm.20004

Barbara, B., Alberto, P., \& Dormio, A. I. (2005). Organizational socialization, career aspirations and turnover intentions among design engineers. Leadership \& Organization Development Journal, 26(6), 424-441.

Berson, Y., Oreg, S., \& Dvir, T. (2008). CEO values, organizational culture and firm outcomes. Journal of Organizational Behavior, 29(5), 615-633. https://doi.org/10.1002/job.499

Brenyah, R. S., \& Darko, T. O. (2017). Organisational Culture and Employee Engagement within the Ghanaian Public Sector. Review of Public Administration and Management, 05(03). https://doi.org/10.4172/2315-7844.1000233

Burke, M. J., Borucki, C. C., \& Hurley, A. E. (1992). Reconceptualizing Psychological Climate in a Retail Service Environment: A Multiple-Stakeholder Perspective. Journal of Applied Psychology, 77(5), 717-729. https://doi.org/10.1037/0021-9010.77.5.717

Cameron, K., \& Quinn, R. (2011). Diagnosing and changing organizational culture: Based on the competing values framework.

Chalofsky, N. E. (2010). Meaningful Workplaces: Reframing How and Where we Work | Wiley.

Chin, W. W., Peterson, R. A., \& Brown, S. P. (2008). Structural equation modeling in marketing: Some practical reminders. In Journal of Marketing Theory and Practice (Vol. 16, Issue 4, pp. 287-298). https://doi.org/10.2753/MTP1069-6679160402

Cohen, S. (1988). Perceived stress in a probability sample of the United States. - PsycNET. Newbury Park, CA: Sage, 31-67. https://psycnet.apa.org/record/1988-98838-002

Dapke, D., \& Patole, S. (2014). Predicting Employee Engagement: Role of Perceived Organizational Support and Perceived Superior Support. Tactful Management Research Journal, 3(1), 1-8.

Deconinck, J., \& Johnson, J. (2009). The effects of perceived supervisor support, perceived organizational support, and organizational justice on turnover among salespeople. Journal of Personal Selling and Sales Management, 29(4), 333-350. https://doi.org/10.2753/PSS0885-3134290403

Eisenberger, R., Stinglhamber, F., Vandenberghe, C., Sucharski, I. L., \& Rhoades, L. (2002). Perceived supervisor support: Contributions to perceived organizational support and employee retention. Journal of Applied Psychology, 87(3), 565-573. https://doi.org/10.1037/0021-9010.87.3.565

Gallup. (2002). "The high cost of disengaged employees.

Hair jr, Joseph F; Hult, G Tomas M; Ringle, Christian; Sarstedt, M. (2016). A Primer on Partial Least Squares Structural Equation Modeling (PLS-SEM) | SAGE Publications Inc. https://us.sagepub.com/en-us/nam/aprimer-on-partial-least-squares-structural-equation-modeling-pls-sem/book244583

Hallberg, U. E., Johansson, G., \& Schaufeli, W. B. (2007). Personality and Social Sciences Type A behavior and work situation: Associations with burnout and work engagement. Scandinavian Journal of Psychology, 48, 135-142. https://doi.org/10.1111/j.1467-9450.2007.00584.x

Henseler, J., Ringle, C. M., \& Sarstedt, M. (2015). A new criterion for assessing discriminant validity in variance-based structural equation modeling. Journal of the Academy of Marketing Science, 43(1), 115-135. https://doi.org/10.1007/s11747-014-0403-8

Hofstede, G., Neuijen, B., Ohayv, D. D., Sanders, G., Administrative, S., Quarterly, S., \& Jun, N. (1990). Administrative Science Quarterly,. 35(2), 286-316.

Holland, P., Cooper, B., \& Sheehan, C. (2017). Employee Voice, Supervisor Support, and Engagement: The 
Mediating Role of Trust. Human Resource Management, 56(6), 915-929.

https://doi.org/10.1002/hrm.21809

J., A. (2014). Determinants of employee engagement and their impact on employee performance. International Journal of Productivity and Performance Management, 63(3), 308-323. https://doi.org/10.1108/IJPPM-012013-0008

Kahn, W. A. (1990). PSYCHOLOGICAL CONDITIONS OF PERSONAL ENGAGEMENT AND

DISENGAGEMENT AT WORK. Academy of Management Journal, 33(4), 692-724.

https://doi.org/10.2307/256287

Kapoor, S., \& Meachem, A. (2012). Employee Engagement-A Bond between Employee and Organisation Human

Resource Management / Behavioural Science View project Employee Engagement-A Bond between Employee and

Organisation. https://www.researchgate.net/publication/303641091

Khazanchi, S., Lewis, M. W., \& Boyer, K. K. (2007). Innovation-supportive culture: The impact of organizational values on process innovation. Journal of Operations Management, 25(4), 871-884.

https://doi.org/10.1016/j.jom.2006.08.003

Kim, J. H. (2019). Multicollinearity and misleading statistical results. Korean Journal of Anesthesiology, 72(6), 558569. https://doi.org/10.4097/kja.19087

Kline, R. B. (2011). Convergence of Structural Equation Modeling and Multilevel Modeling. In The SAGE Handbook of Innovation in Social Research Methods (pp. 562-589). SAGE Publications Ltd. https://doi.org/10.4135/9781446268261.n31

Kristof, A. M. Y. L. (1996). PERSON-ORGANIZATION FIE AN INTEGRATIVE REVIEW OF ITS CONCEPTUALIZATIONS , MEASUREMENT, AND IMPLICATIONS.

Kumi, E., Yeboah, T., \& Kumi, Y. A. (2020). Private sector participation in advancing the Sustainable Development Goals (SDGs) in Ghana: Experiences from the mining and telecommunications sectors. Extractive Industries and Society, 7(1), 181-190. https://doi.org/10.1016/j.exis.2019.12.008

Ladebo, O. J. (2008). Perceived Supervisory Support and Organisational Citizenship Behaviours: Is Job Satisfaction a Mediator? South African Journal of Psychology, 38(3), 479-488. https://doi.org/10.1177/008124630803800303

London, M. (1993). Relationships between career motivation, empowerment and support for career development. Journal of Occupational and Organizational Psychology, 66(1), 55-69. https://doi.org/10.1111/j.2044-8325.1993.tb00516.x

M. Blau, P. (1964). Exchange and Power in Social Life. American Sociological Review, 30(5), 789. https://doi.org/10.2307/2091154

Macey, W. H., \& Schneider, B. (2008). The Meaning of Employee Engagement. Industrial and Organizational Psychology, 1, 3-30.

Masterson, S. S., Lewis, K., Goldman, B. M., \& Taylor, M. S. (2000). Forthcoming in the Academy of Management Journal Integrating Justice and Social Exchange 1 Forthcoming in the Academy of Management Journal Integrating Justice and Social Exchange 2. Academy of Management Journal, 43(4), $738-748$.

Mohamed, S. A., \& Ali, M. (2016). The Impacts of Supervisor Support on Employees' Engagement. International Journal of Research \& Review (Www. Gkpublication.In), 3(March), 3. www.ijrrjournal.com

Njuguna, R. G. (2016). Influence of Organizational Culture on Employee Work Behavior. International Journal of Contemporary Business Studies, 3(11), 46-58.

O'Reilly, C. A., Chatman, J., \& Caldwell, D. F. (1991). PEOPLE AND ORGANIZATIONAL CULTURE: A PROFILE COMPARISON APPROACH TO ASSESSING PERSON-ORGANIZATION FIT. Academy of Management Journal, 34(3), 487-516. https://doi.org/10.5465/256404

Ocampo, R. C. De, Danao, H. N., \& Peña, A. M. (2018). The Relationship Of Perceived Organizational Support And Perceived Supervisor Support To Work Engagement Among BPO-RPO Employees. International Journal of Advanced Research and Publications, 2(9), 97-105.

Ohemeng, F. L. K., Obuobisa Darko, T., \& Amoako-Asiedu, E. (2020). Employee engagement and task 
performance in state-owned enterprises in developing countries: The case study of the power sector in Ghana. Journal of Public Affairs, 20(2), e2021. https://doi.org/10.1002/pa.2021

Othman, A. K., Hamzah, M. I., Abas, M. K., \& Zakuan, N. M. (2017). International Journal of Advanced and Applied Sciences The influence of leadership styles on employee engagement: The moderating effect of communication styles. 4(3), 107-116.

Otken, A. B., \& Erben, G. S. (2010). INVESTIGATING THE RELATIONSHIP BETWEEN ORGANIZATIONAL IDENTIFICATION AND WORK Abstract: ILISSKININ VE AMIR DESTE ĞININ ROLÜNÜN INCELENMESİ Öz: 2, 93-118.

Powell, T. C. (2011). Behaviour Strategy. Journal of Strategic Management, 1369-1386. https://doi.org/10.1002/smj

Rabiul, M., \& Rubel, B. (2013). Perceived Support and Employee Performance: The Mediating Role of Employee Engagement. January.

Saks, A. M. (2006). Antecedents and consequences of employee engagement. Journal of Managerial Psychology, 21(7), 600-619. https://doi.org/10.1108/02683940610690169

Sattavorn, S. (2018). The impact of career satisfaction, commitment and supervisory support on organizational commitment of Thai Employees: A study in Japanese subsidiaries. Proceedings of 20185 th International Conference on Business and Industrial Research: Smart Technology for Next Generation of Information, Engineering, Business and Social Science, ICBIR 2018, June, 344-349. https://doi.org/10.1109/ICBIR.2018.8391219

Sawasdee, A., Saengchai, S., \& Jermsittiparsert, K. (2020). The role of emotional demands, supervisor support and training opportunities towards work engagement among employees in pharmaceutical companies of Thailand. Systematic Reviews in Pharmacy, 11(3), 176-184. https://doi.org/10.5530/srp.2020.3.20

Schaufeli, W. B., \& Bakker, A. B. (2003). Utrecht work engagement scale Preliminary Manual Version 1.1. Occupational Health Psychology Unit Utrecht University, December, 1-60. https:/ / doi.org/10.1037/t01350-000

Schaufeli, Wilmar B., \& Bakker, A. B. (2004). Job demands, job resources, and their relationship with burnout and engagement: A multi-sample study. Journal of Organizational Behavior, 25(3), 293-315. https://doi.org/10.1002/job.248

Schein, E. H. (1996). Culture: The Missing Concept in Studies Organization. 41(2), 229-240.

Seijts, G., \& Crim, D. (2006). What engages employees the most or, the ten C's of employee engagement. Ivey Business Journal, 23(April), 1-6.

http://www.hrpld.ca/newsletters/May2007/EEEngagement.pdf\%5Cnhttp://jsedres.sepmonline.org/c ontent/23/3/143.abstract

Shmueli, G., Sarstedt, M., Hair, J. F., Cheah, J. H., Ting, H., Vaithilingam, S., \& Ringle, C. M. (2019). Predictive model assessment in PLS-SEM: guidelines for using PLSpredict. European Journal of Marketing, 53(11), 2322-2347. https://doi.org/10.1108/EJM-02-2019-0189

Shuck, B., \& Reio, T. G. (2014). Employee Engagement and Well-Being. Journal of Leadership \& Organizational Studies, 21(1), 43-58. https://doi.org/10.1177/1548051813494240

Shusha, A. (2013). The Role of Psychological Engagement in Relationship between Perceived Organizational Support and Withdrawal Behavior and Intentions: An Empirical Study on Small Industries in The Role of Psychological Engagement in Relationship between Perceived Organiza. Article in International Journal of Business and Management, 8(16). https://doi.org/10.5539/ijbm.v8n16p22

Swanberg, J. E., McKechnie, S. P., Ojha, M. U., \& James, J. B. (2011). Schedule control, supervisor support and work engagement: A winning combination for workers in hourly jobs? Journal of Vocational Behavior, 79(3), 613-624. https://doi.org/10.1016/j.jvb.2011.04.012

Vera, M., Martínez, I. M., Lorente, L., \& Chambel, M. J. (2016). The Role of Co-worker and Supervisor Support in the Relationship Between Job Autonomy and Work Engagement Among Portuguese Nurses: A Multilevel Study. Social Indicators Research, 126(3), 1143-1156. https://doi.org/10.1007/s11205-0150931-8 
Wallach, E. J. (1983). Individuals and Organizations: The Cultural Match. In Training \& Development Journal (Vol. 37, Issue 2, pp. 28-36).

http:/ / search.ebscohost.com/login.aspx?direct=true\&db=a9h\&AN=9228168\&site=ehost-live

Warrick, D. D., Milliman, J. F., \& Ferguson, J. M. (2016). Building high performance cultures. Organizational Dynamics, 45(1), 64-70. https://doi.org/10.1016/j.orgdyn.2015.12.008 